Case Series

\title{
Boosting effect of cyclosporine on corticosteroids in the acute management of toxic epidermal necrolysis
}

\author{
Nageswaramma Siddabathuni, Sahitya Tadi, Rakesh Darla*, Premsagar Gomukonda
}

Department of Dermatology and Venereology, Guntur Government Hospital, Guntur, Andhra Pradesh, India

Received: 25 May 2020

Revised: 18 June 2020

Accepted: 20 June 2020

\author{
*Correspondence: \\ Dr. Rakesh Darla, \\ E-mail: sahitya.tadi@gmail.com
}

Copyright: (C) the author(s), publisher and licensee Medip Academy. This is an open-access article distributed under the terms of the Creative Commons Attribution Non-Commercial License, which permits unrestricted non-commercial use, distribution, and reproduction in any medium, provided the original work is properly cited.

\begin{abstract}
Toxic epidermal necrolysis (TEN) is a life-threatening dermatological emergencies. It is a rare, acute mucocutaneous disorder that usually occur secondarily as an idiosyncratic reaction to certain drugs. Prompt identification and discontinuation of the causative drug is mandatory along with adequate supportive care like proper hydration, minimize the number of skin manipulation, prevention of secondary infections. Many immunosuppressive modalities have been tried with variable results. In this manuscript, we reported 12 consecutive cases of TEN presented to our hospital over a period of 2 years from 2017 to 2019. All the cases presented with varying percentage of skin blistering and mucosal involvement secondary to an offending drug. The incriminated drug was discontinued, supportive care was initiated along with combination therapy of cyclosporine and corticosteroids as immunosuppressants. The clinical presentation, etiological drugs and treatment protocol followed and its efficacy will be described in details.
\end{abstract}

Keywords: Corticosteroid, Cyclosporin, TEN

\section{INTRODUCTION}

Toxic epidermal necrolysis (TEN) is a rare and serious skin condition, often caused by an adverse reaction to medications characterized by skin peeling and blistering along with erosions of mucosal surfaces. ${ }^{1}$ World-wide, the average annual incidence of TEN is $0.4-1.3$ cases per million populations. ${ }^{2,3}$ The mortality rate of StevensJohnson syndrome (SJS) and TEN is high; approximately, 5\% for SJS and 30\% for TEN. ${ }^{4,5}$ Now SJS, SJS-TEN overlap and TEN are considered a spectrum of the same condition having common risk factors and causes, differentiated only by the extent of the body surface area (BSA) involved. Patients with epidermal detachment involving less than $10 \%$ of BSA are classified as having SJS, more than $30 \%$ BSA as TEN and $10-30 \%$ as SJS/TEN overlap. ${ }^{6}$ Apoptosis is thought to be the primary reason responsible for keratinocyte death in TEN. Two probable explanation supporting apoptosis for keratinocyte death are noted. The first explanation is activation of cytotoxic T-cells drug and release of granzyme B and perforin, ultimately resulting in activating the caspase cascade and keratinocyte apoptosis. $^{7}$ The second explanation proposes that Fas-Fas ligand binding activates caspase 8 , which results in nuclease activation and the widespread skin blistering characteristic of this severe drug reaction. ${ }^{8}$

A prognostic score called SCORTEN has been validated to demonstrate its ability to specifically predict patient outcome in SJS and TEN. ${ }^{9,10}$ Even though, some uncertainty still persists on effector mechanisms of TEN, the resemblance to graft rejection provided a rational for using the immunomodulating agents. ${ }^{11}$ There are several studies illustrating variable results in the management of TEN. These included corticosteroids, plasmapheresis, cyclophosphamide, thalidomide. ${ }^{12-16}$ Fas-Fas ligand and cytotoxic T-cell, which plays a vital role in the pathogenesis of TEN are respectively blocked by 
intravenous immunoglobulin (IVIG) and cyclosporine. Thus, theoretically making, IVIG and cyclosporine effective drugs in the management of TEN. ${ }^{17}$ Several case reports have suggested encouraging results with IVIG in management of TEN. ${ }^{18-26}$ However, study by Bachot et al did not show any improvement with IVIG. ${ }^{27}$ In Indian subcontinent managing TEN by IVIG is not costeffective and there is no literature backup to suggest IVIG is superior than other modalities. Several case reports and case series revealed encouraging result of use of cyclosporine in stopping disease progression and to prevent the mortality. ${ }^{11,28-34}$ In Indian subcontinent, systemic steroids have traditionally been used to manage TEN because of its easy availability and cost effectiveness. This study was designed to evaluate the efficacy of combination therapy of systemic corticosteroid and cyclosporine in tertiary health-care setting.

\section{CASE SERIES}

Study was conducted at Government General Hospital, Guntur during 01 July 2017 to 30 June 2019. Prior approval of ethical committee was taken. A total of 12 patients were enrolled into the study during this period. All cases fulfilling clinical diagnoses of TEN were included into the study. Exclusion criteria were prior treatment with any other immunosuppressive drugs, history of intolerance to cyclosporine, uncontrolled diabetes mellitus, human immunodeficiency virus (HIV) positivity and cases of multi-organ failure and sepsis.

Treatment protocol used in our study populationinitially, dexamethasone was administered in the dose of $16 \mathrm{mg}$ twice daily for 5 days and was followed by cyclosporine in the dose of $3 \mathrm{mg} / \mathrm{kg}$ body weight in two divided dosage for 07 days and then tapered over another 14 days. No other immunosuppressant was administered. Cases of TEN were managed in the intensive care of Department of Dermatology. Barrier nursing, ambient temperature of $30^{\circ} \mathrm{C}$, fluid and electrolyte balance and high calorie containing diets were considered in each patient. Injectable antibiotics were considered in strongly suspected or evident sepsis.

Efficacy of combination therapy of corticosteroids and cyclosporine was assessed by the average number of days in stabilization of disease progress, rate of reepithelization of skin, duration of hospitalization, safety profile of medications and mortality rate at 1 month in comparison with the mortality rate predicted by SCORTEN at admission. The SCORTEN calculation was done based on Bastuji-Garin et al. ${ }^{9}$ Stabilization of disease was defined when new lesions cease to appear. Progression of disease was evaluated by any increase in erosions, blistering and positive Nikolsky's sign. Reepithelization was defined as complete healing of the skin without any erosion. Total body surface area (TBSA) assessment was like any burn patients, following rule of nine. Monitoring of patients was like well-established intensive care unit (ICU) protocol.

Table 1: Detailed history and findings of the study population.

\begin{tabular}{|ll|}
\hline Parameter & Mean \pm SD \\
\hline Age (years) & $34.09 \pm 15.17$ \\
\hline $\begin{array}{l}\text { Delay between onset and admission } \\
\text { to hospital (days) }\end{array}$ & $2.73 \pm 0.69$ \\
\hline $\begin{array}{l}\text { Total body surface area involved } \\
(\%)\end{array}$ & $23.3 \pm 16.27$ \\
\hline Stabilisation of disease (days) & $3.18 \pm 1.32$ \\
\hline Re-epithelialisation of skin (days) & $14.54 \pm 4.08$ \\
\hline Hospital stay (days) & $18.09 \pm 5.02$ \\
\hline Complications & $\begin{array}{l}\text { One case } \\
\text { developed } \\
\text { symblepheron }\end{array}$ \\
\hline SCORTEN predicted mortality & $\begin{array}{l}10.16 \text { (SD 9.5) } \\
\text { i.e. 1.11 of } 12 \\
\text { patients }\end{array}$ \\
\hline Actual mortality rate & Zero \\
\hline
\end{tabular}

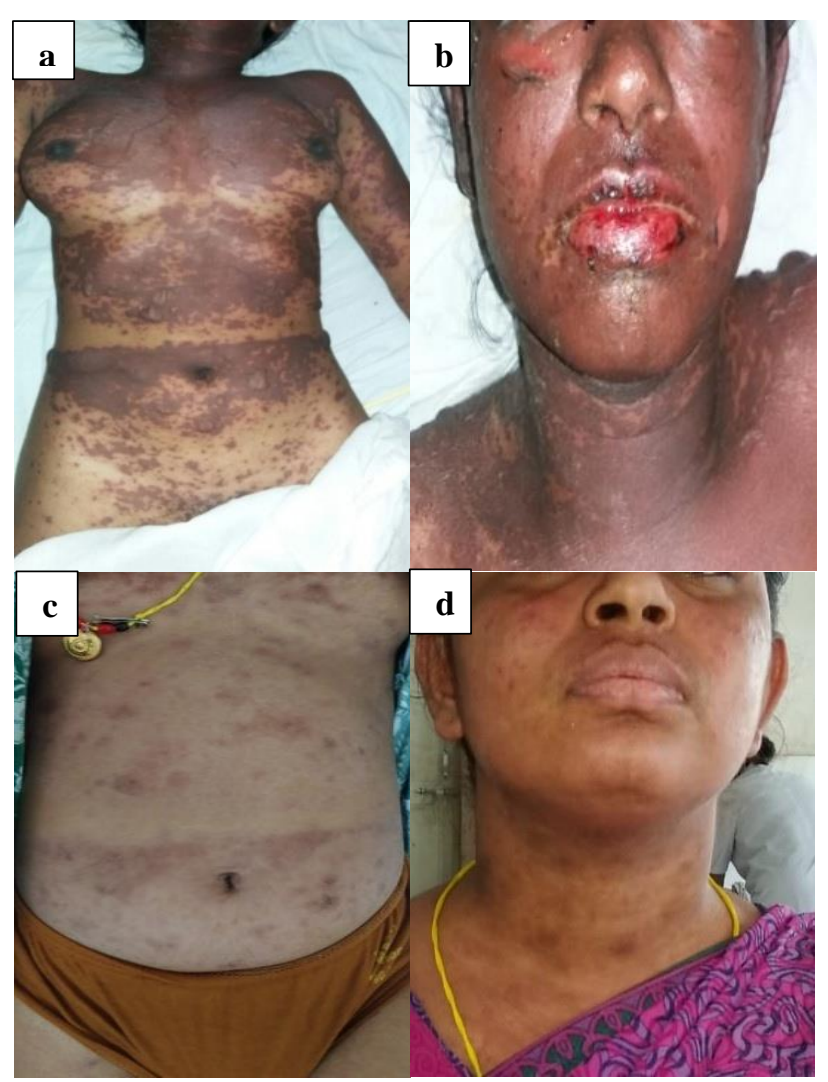

Figure 1: (a and b) Case of TEN caused by taking dilantin orally, treated by a combination of corticosteroids and cyclosporine (left); (c and d) post treatment showing complete recovery (right).

In relation to causative drug, three cases were secondarily to dilantin and ibuprofen each, two to carbamazepine, one each to ofloxacin, ciprofloxacin and amoxicillin. 


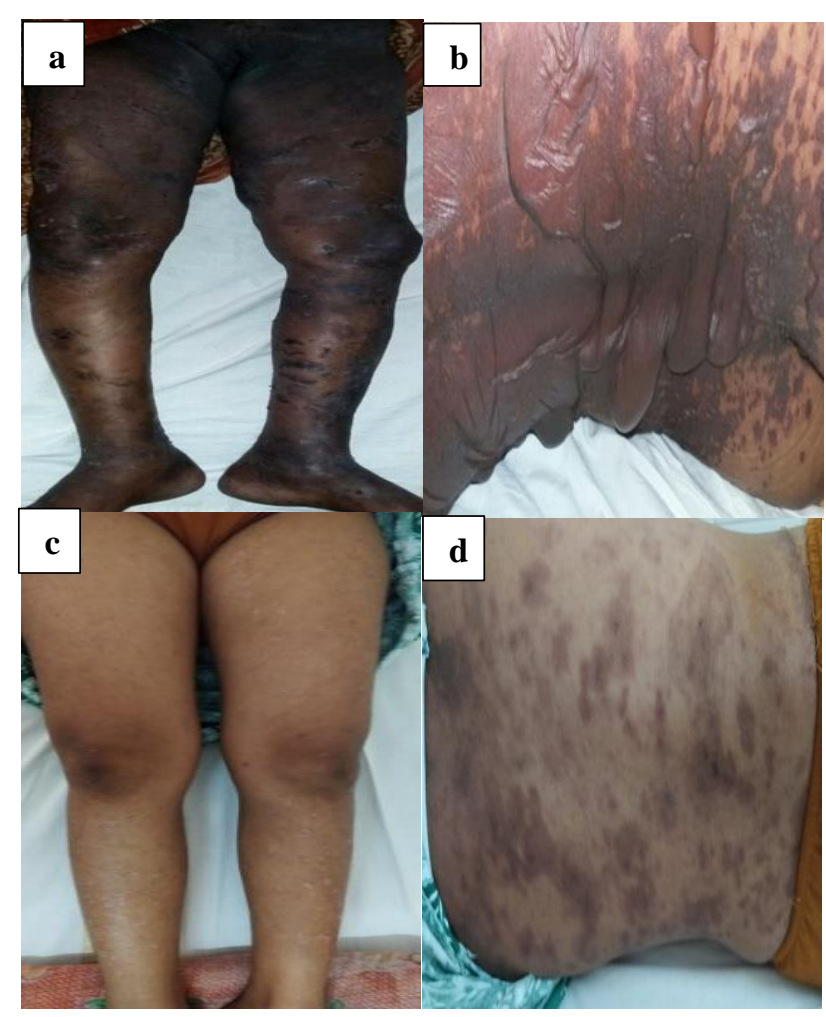

Figure 2: (a and b) Case of TEN caused by taking carbamazepine orally, treated by a combination of corticosteroids and cyclosporine (left); (c and d) post treatment showing complete recovery (right).

\section{DISCUSSION}

The Cochrane review on the management of Toxic epidermal necrolysis showed only one randomized controlled trial. ${ }^{35}$ This trial compared the effectiveness of thalidomide with placebo. The only trial available used thalidomide, but this trial did not show any benefit from treatment compared against placebo, but highlighted increased chances of dying from the treatment. ${ }^{16}$ Role of corticosteroids in treating patients of TEN has been debatable. Several studies had shown possible benefit of corticosteroids. $^{12,36,37}$ However, off late most of the studies criticized the use of corticosteroids stating it not only prolongs the hospital stay, but also make patients susceptible for complications. ${ }^{38,39}$ A retrospective analysis of 289 patients from the EuroSCAR study found no benefit from corticosteroids or IVIG compared to supportive care alone. ${ }^{40}$ Even, the combination therapy of corticosteroid and IVIG had no positive impact on the mortality rate. ${ }^{18}$

Withdrawal of causative drugs should be a priority in the management of TEN, as there is paucity of data on effective drug for TEN. Doval et al have shown that longer the half-life of the causative drug, poorer is the prognosis and suggested early withdrawal of the causative drug. ${ }^{40}$ In order to identify the culprit drug, it is important to consider the chronology of administration of the drug and the reported ability of the drug to induce
SJS/TEN. TEN is a life threatening disease and proper supervision with timely intervention is an integral part of the management. ${ }^{1}$

Our study was distinct in the way, it had evaluated the efficacy of combination therapy of corticosteroid and cyclosporine in cases of TEN. It highlighted few important results. Cyclosporine was well tolerated by all the patients. There was no death in the patients managed by combination therapy of corticosteroid and cyclosporine. All the above findings were statistically significant with $\mathrm{p}$ value less than 0.05 . Only one patient who inadvertently continued using ofloxacin eye drops, which was the culpable oral drug for the development of TEN. The same could be the basis for continuation of BSA involvement despite being administered cyclosporine. $100 \%$ survival in cyclosporine group could be explained by probable mechanism of action of this drug, which targets cytotoxic T-cell, which plays an important role in the apoptosis of keratinocytes. Other probable reason could be strict exclusion of patients of HIV, sepsis and multi organ dysfunction, who are likely to succumb to death when they develop TEN.

Recently, Valeyrie-Allanore et al conducted an open, phase II trial to determine the safety and possible benefit of cyclosporine. ${ }^{11}$ A total of 29 patients were included in the trial (10 SJS, 7 TEN and 12 SJS/TEN overlap), and 26 patients completed the treatment protocol of oral cyclosporine at a dose of $3 \mathrm{mg} / \mathrm{kg} /$ day for 10 days and gradually tapered over one month. Results show a possible usefulness of cyclosporine in SJS and TEN, as the mortality rate and progression of the disease is much lower than the expected value.

In a case series reported by Arévalo et al in which 11 patients treated with oral cyclosporine $3 \mathrm{mg} / \mathrm{kg} / \mathrm{day}$ observed a rapid epithelialization with no significant toxicity in comparison with patients treated with combination of corticosteroids and cyclophosphamide $(\mathrm{n}=6) .^{31}$

Our study show very good results with the treatment protocol; however, comment on its efficacy cannot be made due to in built constrain of the study design. Very small sample size and exclusion of complicated cases are obvious limitations of this study, which may have added to the favourable outcome of combination therapy of corticosteroid and cyclosporine.

\section{CONCLUSION}

The present study suggest that combination therapy of corticosteroid and cyclosporine has a definite role in treating uncomplicated cases of TEN. Though a large, double-blind, placebo-controlled, randomized trial would prove the efficacy of the treatment protocol beyond any doubts, it is highly unpractical. 
Funding: No funding sources

Conflict of interest: None declared

Ethical approval: Not required

\section{REFERENCES}

1. Roujeau JC, Stern RS. Severe adverse cutaneous reactions to drugs. N Engl J Med. 1994;331:127285.

2. Abood GJ, Nickoloff BJ, Gamelli RL. Treatment strategies in toxic epidermal necrolysis syndrome: Where are we at? J Burn Care Res. 2008;29:269-76.

3. Mockenhaupt M, Viboud C, Dunant A, Naldi L, Halevy S, Bouwes Bavinck JN, et al. StevensJohnson syndrome and toxic epidermal necrolysis: Assessment of medication risks with emphasis on recently marketed drugs. The EuroSCAR-study. J Invest Dermatol. 2008;128:35-44.

4. Revuz J, Penso D, Roujeau JC, Guillaume JC, Payne CR, Wechsler J, et al. Toxic epidermal necrolysis. Clinical findings and prognosis factors in 87 patients. Arch Dermatol. 1987;123:1160-5.

5. Schöpf E, Stühmer A, Rzany B, Victor N, Zentgraf R, Kapp JF. Toxic epidermal necrolysis and Stevens-Johnson syndrome. An epidemiologic study from West Germany. Arch Dermatol. 1991;127:839-42.

6. Auquier-Dunant A, Mockenhaupt M, Naldi L, Correia O, Schröder W, Roujeau JC, et al. Correlations between clinical patterns and causes of erythema multiforme majus, Stevens-Johnson syndrome, and toxic epidermal necrolysis: Results of an international prospective study. Arch Dermatol. 2002;138:1019-24.

7. Pereira FA, Mudgil AV, Rosmarin DM. Toxic epidermal necrolysis. J Am Acad Dermatol. 2007;56:181-200.

8. Wehrli P, Viard I, Bullani R, Tschopp J, French LE. Death receptors in cutaneous biology and disease. $\mathrm{J}$ Invest Dermatol. 2000;115:141-8.

9. Guégan S, Bastuji-Garin S, Poszepczynska-Guigné E, Roujeau JC, Revuz J. Performance of the SCORTEN during the first five days of hospitalization to predict the prognosis of epidermal necrolysis. J Invest Dermatol. 2006;126:272-6.

10. Bastuji-Garin S, Fouchard N, Bertocchi M, Roujeau JC, Revuz J, Wolkenstein P. SCORTEN: A severity-of-illness score for toxic epidermal necrolysis. J Invest Dermatol. 2000;115:149-53.

11. Valeyrie-Allanore L, Wolkenstein P, Brochard L, Ortonne N, Maître B, Revuz J, et al. Open trial of ciclosporin treatment for Stevens-Johnson syndrome and toxic epidermal necrolysis. $\mathrm{Br} \mathrm{J}$ Dermatol. 2010;163:847-53.

12. Patterson R, Miller M, Kaplan M, Doan T, Brown J, Detjen $\mathrm{P}$, et al. Effectiveness of early therapy with corticosteroids in Stevens-Johnson syndrome: Experience with 41 cases and a hypothesis regarding pathogenesis. Ann Allerg. 1994;73:27-34.
13. Chaidemenos GC, Chrysomallis F, Sombolos K, Mourellou O, Ioannides D, Papakonstantinou M. Plasmapheresis in toxic epidermal necrolysis. Int $\mathbf{J}$ Dermatol. 1997;36:218-21.

14. Egan CA, Grant WJ, Morris SE, Saffle JR, Zone JJ. Plasmapheresis as an adjunct treatment in toxic epidermal necrolysis. J Am Acad Dermatol. 1999;40:458-61.

15. Heng MC, Allen SG. Efficacy of cyclophosphamide in toxic epidermal necrolysis. Clinical and pathophysiologic aspects. J Am Acad Dermatol. 1991;25:778-86.

16. Wolkenstein P, Latarjet J, Roujeau JC, Duguet C, Boudeau S, Vaillant L, et al. Randomised comparison of thalidomide versus placebo in toxic epidermal necrolysis. Lancet. 1998;352:1586-9.

17. Fernando SL. The management of toxic epidermal necrolysis. Australas J Dermatol. 2012;53:165-71.

18. Yang Y, Xu J, Li F, Zhu X. Combination therapy of intravenous immunoglobulin and corticosteroid in the treatment of toxic epidermal necrolysis and Stevens-Johnson syndrome: A retrospective comparative study in China. Int $\mathrm{J}$ Dermatol. 2009;48:1122-8.

19. Stella M, Clemente A, Bollero D, Risso D, Dalmasso P. Toxic epidermal necrolysis (TEN) and Stevens-Johnson syndrome (SJS): Experience with high-dose intravenous immunoglobulins and topical conservative approach. A retrospective analysis. Burns. 2007;33:452-9.

20. Tristani-Firouzi P, Petersen MJ, Saffle JR, Morris SE, Zone JJ. Treatment of toxic epidermal necrolysis with intravenous immunoglobulin in children. J Am Acad Dermatol. 2002;47:548-52.

21. Campione E, Marulli GC, Carrozzo AM, Chimenti MS, Costanzo A, Bianchi L. High-dose intravenous immunoglobulin for severe drug reactions: Efficacy in toxic epidermal necrolysis. Acta Derm Venereol. 2003;83:430-2.

22. Metry DW, Jung P, Levy ML. Use of intravenous immunoglobulin in children with Stevens-Johnson syndrome and toxic epidermal necrolysis: Seven cases and review of the literature. Pediatrics. 2003;112:1430-6.

23. Prins C, Kerdel FA, Padilla RS, Hunziker T, Chimenti S, Viard I, et al. Treatment of toxic epidermal necrolysis with high-dose intravenous immunoglobulins: Multicenter retrospective analysis of 48 consecutive cases. Arch Dermatol. 2003;139:26-32.

24. Al-Mutairi N, Arun J, Osama NE, Amr Z, Mazen AS, Ibtesam EA, et al. Prospective, noncomparative open study from Kuwait of the role of intravenous immunoglobulin in the treatment of toxic epidermal necrolysis. Int J Dermatol. 2004;43:847-51.

25. Tan AW, Thong BY, Yip LW, Chng HH, Ng SK. High-dose intravenous immunoglobulins in the treatment of toxic epidermal necrolysis: An Asian series. J Dermatol. 2005;32:1-6. 
26. Mangla K, Rastogi S, Goyal P, Solanki RB, Rawal RC. Efficacy of low dose intravenous immunoglobulins in children with toxic epidermal necrolysis: An open uncontrolled study. Indian J Dermatol Venereol Leprol. 2005;71:398-400.

27. Bachot N, Revuz J, Roujeau JC. Intravenous immunoglobulin treatment for Stevens-Johnson syndrome and toxic epidermal necrolysis: A prospective noncomparative study showing no benefit on mortality or progression. Arch Dermatol. 2003;139:33-6.

28. Zaki I, Patel S, Reed R, Dalziel KL. Toxic epidermal necrolysis associated with severe hypocalcaemia, and treated with cyclosporin. $\mathrm{Br} \mathrm{J}$ Dermatol. 1995;133:337-8.

29. Sullivan JR, Watson A. Lamotrigine-induced toxic epidermal necrolysis treated with intravenous cyclosporin: A discussion of pathogenesis and immunosuppressive management. Australas J Dermatol. 1996;37:208-12.

30. Jarrett P, Rademaker M, Havill J, Pullon H. Toxic epidermal necrolysis treated with cyclosporin and granulocyte colony stimulating factor. Clin Exp Dermatol. 1997;22:146-7.

31. Arévalo JM, Lorente JA, González-Herrada C, Jiménez-Reyes J. Treatment of toxic epidermal necrolysis with cyclosporin A. J Trauma. 2000;48:473-8.

32. Robak E, Robak T, Góra-Tybor J, Chojnowski K, Strzelecka B, Waszczykowska E, et al. Toxic epidermal necrolysis in a patient with severe aplastic anemia treated with cyclosporin A and GCSF. J Med. 2001;32:31-9.

33. Hashim N, Bandara D, Tan E, Ilchyshyn A. Early cyclosporine treatment of incipient toxic epidermal necrolysis induced by concomitant use of lamotrigine and sodium valproate. Acta Derm Venereol. 2004;84:90-1.
34. Rai R, Srinivas CR. Suprapharmacologic doses of intravenous dexamethasone followed by cyclosporine in the treatment of toxic epidermal necrolysis. Indian J Dermatol Venereol Leprol. 2008;74:263-5.

35. Majumdar S, Mockenhaupt M, Roujeau J, Townshend A. Interventions for toxic epidermal necrolysis. Cochrane Database Syst Rev. 2002;CD001435.

36. Kakourou T, Klontza D, Soteropoulou F, Kattamis C. Corticosteroid treatment of erythema multiforme major $\mathrm{n}$ (Stevens-Johnson syndrome) in children. Eur J Pediatr. 1997;156:90-3.

37. Tripathi A, Ditto AM, Grammer LC, Greenberger PA, McGrath KG, Zeiss CR, et al. Corticosteroid therapy in an additional 13 cases of StevensJohnson syndrome: A total series of 67 cases. Allerg Asthma Proc. 2000;21:101-5.

38. Chave TA, Mortimer NJ, Sladden MJ, Hall AP, Hutchinson PE. Toxic epidermal necrolysis: Current evidence, practical management and future directions. Br J Dermatol. 2005;153:241-53.

39. Gerdts B, Vloemans AF, Kreis RW. Toxic epidermal necrolysis: 15 years' experience in a Dutch burns centre. J Eur Acad Dermatol Venereol. 2007;21:781-8.

40. Schneck J, Fagot JP, Sekula P, Sassolas B, Roujeau JC, Mockenhaupt M. Effects of treatments on the mortality of Stevens-Johnson syndrome and toxic epidermal necrolysis: A retrospective study on patients included in the prospective EuroSCAR Study. J Am Acad Dermatol. 2008;58:33-40.

Cite this article as: Siddabathuni N, Tadi S, Darla $\mathrm{R}$, Gomukonda P. Boosting effect of cyclosporine on corticosteroids in the acute management of toxic epidermal necrolysis. Int J Res Dermatol 2020;6:548-52. 